\title{
Effects of Folic Acid-Fortified Milk Consumption on Serum Folate Levels in Japanese Female Students: a Randomized Controlled Trial Stratified by Methylenetetrahydrofolate Reductase C677T Genetic Polymorphism
}

\section{Chiyogiku Mitsuguchi', Yoshiko Kumagai ${ }^{2}$, Hiroko Yasutomo ${ }^{2}$, Yuuki Ito ${ }^{2}$, Motoji Kitagawa1, Kotoyo Fujiki ${ }^{1}$ and Yuko Tokudome ${ }^{1}$}

${ }^{1}$ Graduate School of Nutritional Sciences, Nagoya University of Arts and Sciences, Japan

${ }^{2}$ School of Nutritional Sciences, Nagoya University of Arts and Sciences, Japan

\begin{abstract}
Objective: We studied effects of fermented milk fortified with $200 \mu \mathrm{g}$ of folic acid (FF milk) on serum folate levels in Japanese female university students.

Methods: Adopting FF milk as an intervention factor, a randomized controlled trial stratified by the methylenetetrahydrofolate reductase (MTHFR) C677T genetic polymorphism was conducted in 143 university female students. Experimental group subjects were requested to consume FF milk for 4 weeks; control group subjects to consume usual meals. Dietary surveys were conducted using a food frequency questionnaire, and serum folate concentrations were analyzed adopting a chemiluminescence immunoassay. Utilizing oral mucous membrane swabs, MTHFR genotypes were determined with polymerase chain reaction followed by restriction fragment length polymorphism. Paired $t$-test, one-way analysis of variance, Pearson correlation coefficient, chi-square test, or Fisher's exact probability test was applied as appropriate.
\end{abstract}

Results: MTHFR genotype frequencies were as follows: CC, 36 (25.2\%); CT, 75 (52.4\%); and TT, 32 (22.4\%). Subjects were randomly stratified into experimental group $(n=73 ; C C, 16 ; C T, 41 ; T T, 16)$ and control group $(n=70$; $\mathrm{CC}, 20$; CT, 34; TT, 16). Average folate consumption was $246 \mu \mathrm{g} /$ day. Baseline serum folate level was $9.8 \mathrm{ng} / \mathrm{mL}$ on average with significant differences according to MTHFR genotype $(C C>C T>T T)$. Average serum folate concentrations increased by 1.5 in the experimental group after the intervention. At baseline, 19 participants had serum folate levels lower than the cutoff value for neural tube defects (NTDs) $(7 \mathrm{ng} / \mathrm{mL}$; CC, 1/36; CT, 10/75; and TT, 8/32) with significant discrepancies by MTHFR genotype. After the intervention, the number of participants in the experimental group with lower serum folate levels decreased from 10 to $2(\mathrm{CT}, 1 ; \mathrm{TT}, 1)$.

Conclusions: Serum folate levels increased in the experimental group subjects after the intervention, suggesting that consumption of the FF milk sufficiently elevated serum folate concentrations for prevention of NTDs, irrespective of MTHFR genotypes.

Keywords:Folic acid; Milk; Fortification; Randomized controlled trial; Neural tube defects; Serum folate; Methylenetetrahydrofolate reductase $\mathrm{C} 677 \mathrm{~T}$

\section{Introduction}

The human fetal neural tube closes at approximately 4 weeks of conception. During this period, folate deficiency elevates the risk of neural tube defects (NTDs). Many epidemiologic studies have reported that additional consumption of folic acid before and during the early gestation period decreases NTD development [1-5]. After these observations, many countries recommended the consumption of supplements containing $400 \mu \mathrm{g}$ or more of folic acid or of folic acidfortified food from 4 weeks before to 12 weeks after conception, in addition to dietary folate from regular meals [6,7].

In 1999, a large intervention trial in China using a supplement containing $400 \mu \mathrm{g}$ of folic acid reduced NTD development by between $40 \%$ (in lower prevalent areas) and $80 \%$ (in higher prevalent areas) [8]. Since 2000, as in western countries, the Ministry of Health, Labour, and Welfare, Japan, has advised women who could potentially become pregnant, women planning to become pregnant, and pregnant women to consume $400 \mu \mathrm{g} /$ day of folic acid in addition to dietary folate from well-balanced daily meals [9].

Generally speaking, women notice signs of pregnancy after 8-12 weeks of gestation and deliberately begin to consume folic acid supplements [10-16], but it may be too late by then. Folate should be consumed from 4 weeks before to 12 weeks after gestation when neural tubes are formed and closed. However, most Japanese people prefer to consume nutrients from food, not from chemically synthesized folic acid supplements, in view of food security and safety. Supplement consumption rates during the early pregnancy period ranged from $50 \%$ to $70 \%$ in Japanese women $[15,16]$, which is lower than the $70 \%$ to $96 \%$ reported in women in western countries [11-14]. The consumption rates before pregnancy were as low as $20 \%$ to $30 \%$ in both western countries and Japan [10-16].

The National Survey of Health and Nutrition, Japan (2014) reported that average dietary folate consumption from daily meals in young (potentially becoming pregnant) women aged 15-49 ranged from 232 to $243 \mu \mathrm{g} /$ day [17], showing that approximately $50 \%$ were consuming $240 \mu \mathrm{g} /$ day less than the recommended dietary allowance of Dietary Reference Intakes (DRIs) for the Japanese population (2015) [18]. Moreover, this would cause even greater folate insufficiency during pregnancy when higher folate consumption is really needed.

In the present study, we recruited Japanese university students

*Corresponding author: Tokudome Y, Graduate School of Nutritional Sciences Nagoya University of Arts and Sciences, Japan, Tel: +81-561-75-2192; E-mail: tokudome@nuas.ac.jp

Received September 08, 2017; Accepted September 18, 2017; Published September 25, 2017

Citation: Mitsuguchi C, Kumagai Y, Yasutomo H, Ito Y, Kitagawa M, et al. (2017) Effects of Folic Acid-Fortified Milk Consumption on Serum Folate Levels in Japanese Female Students: a Randomized Controlled Trial Stratified by Methylenetetrahydrofolate Reductase C677T Genetic Polymorphism. Vitam Miner 6: 170.

Copyright: () 2017 Mitsugukuchi C, et al. This is an open-access article distributed under the terms of the Creative Commons Attribution License which permits unrestricted use, distribution, and reproduction in any medium, provided the original author and source are credited. 
who could potentially become pregnant, studied the intake of folate from regular meals, and conducted a randomized controlled trial (RCT) using Bifidobacterium-fermented milk fortified with a lower dose of folic acid $(200 \mu \mathrm{g} / 100 \mathrm{~mL}$; FF milk) to examine serum folate concentrations according to the methylenetetrahydrofolate reductase (MTHFR) C677T genetic polymorphism in order to determine if this approach could secure healthy serum folate levels.

\section{Materials and Methods}

\section{Subjects}

We invited 154 non-pregnant female university students (aged 1819 years) attending a university located in $\mathrm{N}$ city, an urban area of Aichi Prefecture, Japan. We excluded 11 subjects ( 2 with hemolysis in blood samples and 9 unavailable for blood sampling after the intervention) from the analysis, but included 4 subjects with lower compliance in the experimental group in reference to the intention-to-treat principle. Thus, 143 subjects were included in the trial. Neither the experimental nor control group subjects had the habit of consuming folic acid supplements.

\section{Study design}

We conducted this RCT after stratifying subjects according to the MTHFR C677T genotype (CC [wild-] type, CT [hetero-] type, and TT [mutant] type) and randomly allocating them into experimental and control groups (Figure 1).

The experimental group was recommended to consume a container of FF milk a day at any time in addition to regular meals for 4 weeks from October to November 2014, and the control subjects were advised to only consume regular meals.

\section{Subjects' characteristics}

Height and weight were measured, and body mass index (BMI=kg/ $\mathrm{m}^{2}$ ) was calculated. Residential type, smoking, drinking habits, and consumption of vitamins and supplements were recorded.

\section{FF milk}

As experimental food, we used FF milk (a commercially available container of fermented milk fortified with folic acid $200 \mu \mathrm{g} / 100 \mathrm{~mL}$ with Bifidobacterium breve strain Yakult (Yakult Honsha Co. Ltd). The ingredients in detail were shown in (Table 1).

We estimated $340 \mu \mathrm{g}$ of dietary folate equivalent (DFE) for folic acid $200 \mu$ g multiplying by $1.7[6,19,20]$.

\section{Assessment of dietary intake}

At baseline and after intervention, a validity and reproducibilityverified self-administered food frequency questionnaire was adopted to survey habitual dietary intake for the previous month [21]. Nutrient calculation was based on the weighed contents of foods and food groups according to the Japanese Standard Food Composition, 5th Edition [22]. Adopting the nutrient-density method, we computed the energy-adjusted $(/ 1,000 \mathrm{kcal})$ intake of folate and related nutrients (including vitamin $\mathrm{B}_{6}$, and vitamin $\mathrm{B}_{12}$ ) to adjust for body size and level of physical activity.

Folate intakes were evaluated with reference to estimated average requirements of $200 \mu \mathrm{g} /$ day when not pregnant and of $400 \mu \mathrm{g} / \mathrm{day}$ when pregnant, as reported in the DRIs for Japanese women (2015) [18].

\section{Analyses of blood biomarkers}

Using morning fasting blood samples, serum folic acid was analyzed

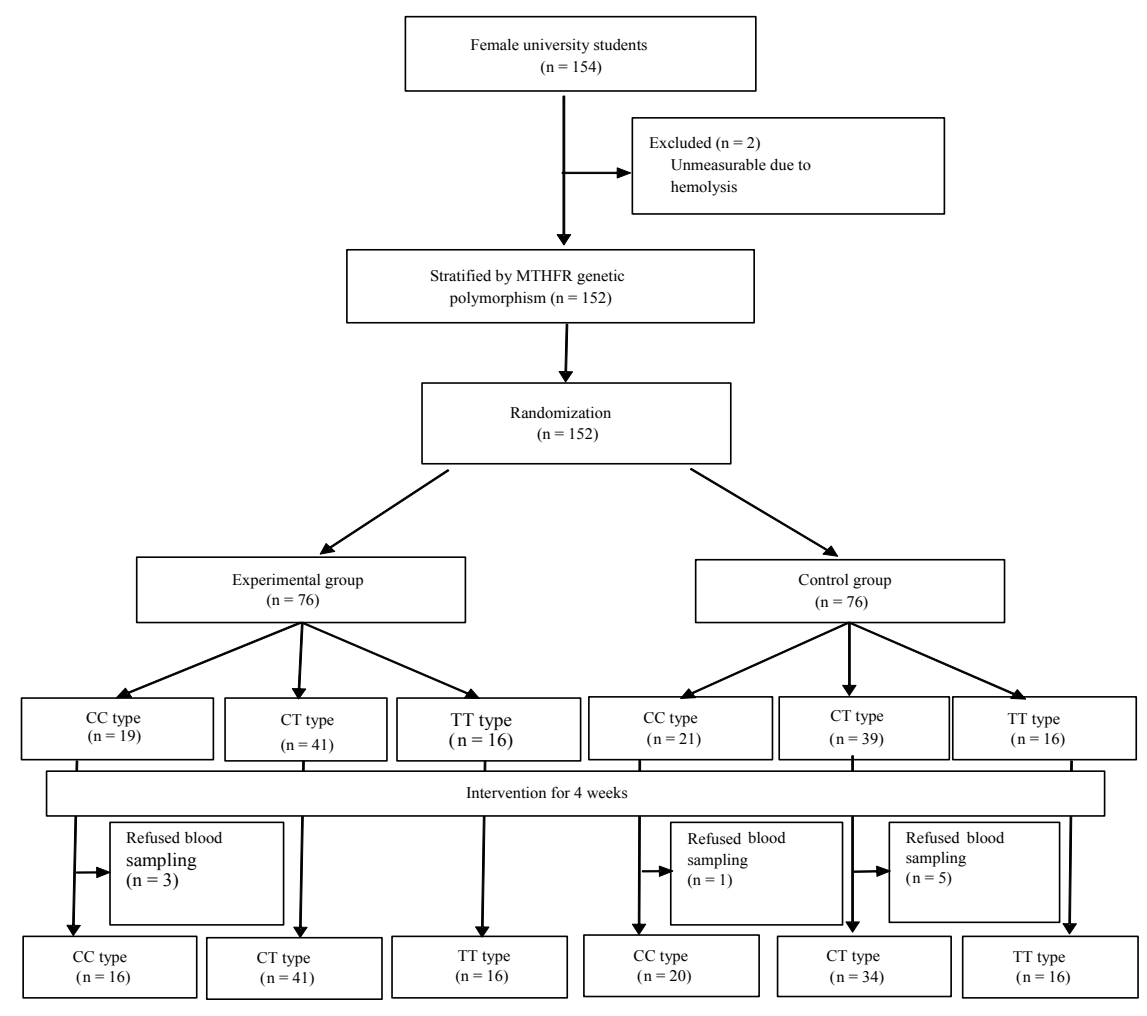

Figure 1: Study flowchart. 
according to a chemiluminescence immunoassay at a commercial laboratory (BioMedical Laboratory). Folate levels were evaluated in reference to a cutoff level $<4 \mathrm{ng} / \mathrm{mL}$ of megaloblastic anemia [23], or $<7 \mathrm{ng} / \mathrm{mL}$ of NTDs [24].

\section{Genetic polymorphism analyses}

Using swabbed oral membranes, the MTHFR C677T genetic polymorphism was determined by polymerase chain reaction (PCR) followed by restriction fragment length polymorphism analysis on a $3 \%$ agarose gel. The following sense and antisense primers were used: 5'TATTGGCAGGTTACCCCAAA3' and 5'CTCACCTGGATGGGAAAGAT3'. The PCR product (208 bp) was digested with restriction enzyme (HinfI) at C677T, resulting in 85 and $123 \mathrm{bp}$ bands for mutant homozygote, 85,123 , and $208 \mathrm{bp}$ bands for heterozygote, and $208 \mathrm{bp}$ band for wild-type homozygote.

\begin{tabular}{|c|c|}
\hline Ingredient & Content/100 $\mathbf{~ L L}$ \\
\hline Energy $($ Kcal) & 49 \\
\hline Protein $(\mathrm{g})$ & 3.2 \\
\hline Fat $(\mathrm{g})$ & 0.1 \\
\hline Carbohydrate $(\mathrm{g})$ & 10.6 \\
\hline Dietary fiber $(\mathrm{g})$ & 2.5 \\
\hline Sodium $(\mathrm{mg})$ & 40 \\
\hline Calcium $(\mathrm{mg})$ & 100 \\
\hline Iron $(\mathrm{mg})$ & 4 \\
\hline Vitamin $\mathrm{B}_{6}(\mathrm{mg})$ & 1.2 \\
\hline Vitamin $\mathrm{B}_{12}(\mu \mathrm{g})$ & 2.4 \\
\hline Vitamin $\mathrm{E}(\mathrm{mg})$ & 8 \\
\hline Folic acid $(\mu \mathrm{gg})$ & 200 \\
\hline
\end{tabular}

\section{Statistical analyses}

Hardy-Weinberg equilibriums of MTHFR genetic polymorphisms were verified by chi-square test. Distributions of serum folate values were skewed, and the natural log transformation was adopted. Chisquare test or Fisher's exact probability test was used to analyze discrete variables. The arithmetic mean [standard deviation (SD)] was calculated for normally distributed parameters, but the geometric mean [SD] was used for natural log-transformed variables. One-way analysis of variance (ANOVA) was used to verify multiple group comparisons, and paired $t$-test to examine baseline versus post-intervention comparisons. Pearson product-moment correlation coefficients were calculated to test associations between folate intakes (nutrient-density method) and natural log-transformed serum folate concentrations. Statistical analyses were conducted using IBM SPSS Statistics ver. 20 and $\mathrm{p}<0.05$ (two-tailed) was considered statistically significant.

\section{Ethical issues}

The Protocol was submitted to the Ethics Committee of Nagoya University of Arts and Sciences (\#101) and approved. Written information was fully given to the subjects, and written consent was obtained from each subject.

\section{Results}

\section{Baseline subjects' characteristics}

The frequencies of the MTHFR C677T genetic polymorphism of all subjects $(\mathrm{n}=143)$ were as follows: CC type, 36 (25.2\%); CT type, 75 (52.4\%); and TT type, 32 (22.4\%). The genotype distributions were

Table 1: Bifidobacterium-fermented milk fortified with folic acid.

\begin{tabular}{|c|c|c|c|c|c|}
\hline & All $(n=143)$ & CC type $(n=36)$ & CT type $(n=75)$ & TT type $(n=32)$ & $\mathbf{P}^{1)}$ \\
\hline \multicolumn{6}{|c|}{ Characteristics } \\
\hline Age (yrs) & 18 [18-19] & $18[18-19]$ & 18 [18-19] & 18 [18-19] & n.s. \\
\hline Height (cm) & $157.9[5.7]$ & $156.9[6.2]$ & $157.4[7.3]$ & $158.5[5.3]$ & n.s. \\
\hline Weight (kg) & $50.2[6.3]$ & $50.2[8.3]$ & $50[6.6]$ & $50.5[5.4]$ & n.s. \\
\hline BMI $\left(\mathrm{kg} / \mathrm{m}^{2}\right)$ & $20.1[1.9]$ & $20.4[1.9]$ & $20.3[4.2]$ & $20.1[1.8]$ & n.s. \\
\hline \multicolumn{6}{|c|}{ Lifestyle habits } \\
\hline \multicolumn{6}{|c|}{ Smoking } \\
\hline Yes (n (\%)) & $1(0.7)$ & $1(2.8)$ & $0(0)$ & $0(0)$ & \\
\hline No $(\mathrm{n}(\%))$ & $140(97.9)$ & $34(94.4)$ & $74(98.7)$ & $32(100)$ & n.s. \\
\hline Non-response (n (\%)) & $2(1.4)$ & $1(2.8)$ & $1(1.3)$ & $0(0)$ & \\
\hline \multicolumn{6}{|c|}{ Alcohol } \\
\hline Yes (n (\%)) & $1(0.7)$ & $1(2.8)$ & $0(0)$ & $0(0)$ & \\
\hline No $(\mathrm{n}(\%))$ & 140 (97.9) & $34(94.4)$ & $74(98.7)$ & $32(100)$ & n.s. \\
\hline Non-response (n (\%)) & $2(1.4)$ & $1(2.8)$ & $1(1.3)$ & $0(0)$ & \\
\hline \multicolumn{6}{|c|}{ Intake of Supplements } \\
\hline Yes (n (\%)) & $16(11.1)$ & $4(11.1)$ & $9(12.0)$ & $3(9.4)$ & \\
\hline No $(\mathrm{n}(\%))$ & $125(87.4)$ & $32(88.9)$ & $64(85.3)$ & $29(90.6)$ & n.s. \\
\hline Non-response (n (\%)) & $2(1.3)$ & $0(0)$ & $2(2.7)$ & $0(0)$ & \\
\hline \multicolumn{6}{|c|}{ Nutrient Intake } \\
\hline Total energy (kcal/day) & $1,559[367]$ & $1,556[379]$ & $1,591[367]$ & $1,487[356]$ & n.s. \\
\hline Vitamin $B_{6}(\mathrm{mg} / 1000 \mathrm{kcal} / \mathrm{day})$ & $0.61[0.14]$ & $0.61[0.14]$ & $0.61[0.13]$ & $0.61[0.18]$ & n.s. \\
\hline Vitamin $B_{12}(\mu \mathrm{g} / 1000 \mathrm{kcal} / \mathrm{day})$ & $2.6[1.1]$ & $2.8[1.0]$ & $2.6[1.2]$ & $2.4[1.1]$ & n.s. \\
\hline Dietary folate $(\mu \mathrm{g} / \mathrm{day})$ & 246 [97] & 251 [93] & 246 [106] & $240[82]$ & n.s. \\
\hline Dietary folate $(\mu \mathrm{g} / 1000 \mathrm{kcal} /$ day $)$ & $159[59]$ & $165[68]$ & $153[46]$ & 169 [73] & n.s. \\
\hline \multicolumn{6}{|c|}{ Serum folate } \\
\hline Serum folate $(\mathrm{ng} / \mathrm{mL})^{2)}$ & $98[1.4]$ & $12.1[1.3]^{a, b}$ & $9.9[1.4]^{a, c}$ & $7.7[1.4]^{a, c}$ & $<0.001$ \\
\hline Serum folate $<7 \mathrm{ng} / \mathrm{mL}(\mathrm{n}(\%))$ & $19(13.3)$ & $1(2.8)$ & $10(13.3)$ & $8(25.0)$ & 0.026 \\
\hline
\end{tabular}

Table 2: Subjects' characteristics, nutrient intakes and serum folate concentrations by MTHFR genetic polymorphism at baseline. 
within the Hardy-Weinberg equilibrium.

The average BMI of the participants was $20.1[1.9] \mathrm{kg} / \mathrm{m}^{2}$ (mean [SD]) (Table 2).

The proportions of non-smokers and non-drinkers were approximately $98 \%$ because the participants were younger than 20 years old (the legal age for alcohol consumption and smoking in Japan). No significant differences were observed in anthropometric characteristics or lifestyle habits across the three MTHFR genotypes.

The average nutrient intake levels for all subjects were as follows: energy, 1,559 [367] kcal/day; vitamin $\mathrm{B}_{6}, 0.61[0.14] \mathrm{mg} / 1,000 \mathrm{kcal} /$ day; vitamin $\mathrm{B}_{12}, 2.6[1.1] \mu \mathrm{g} / 1,000 \mathrm{kcal} /$ day; and dietary folate, 159 [59] $\mu \mathrm{g} / 1,000 \mathrm{kcal} /$ day. There were no significant discrepancies in energy or nutrient intake across MTHFR genetic polymorphisms.

Baseline serum folate levels were $9.8[1.4] \mathrm{ng} / \mathrm{mL}$ on average, and $12.1[1.3] \mathrm{ng} / \mathrm{mL}$ for the CC type, $9.9[1.4] \mathrm{ng} / \mathrm{mL}$ for the CT type, and $7.7[1.4] \mathrm{ng} / \mathrm{mL}$ for the TT type, with significant differences according to MTHFR genotype, in the following order: CC type $>$ CT type $>$ TT type $(\mathrm{p}<0.001)$.

Overall, 19 participants (13.3\%) had a serum folate level lower than $7 \mathrm{ng} / \mathrm{mL}$ (the cutoff value for NTDs; 1 [2.8\%] with the CC type, 10 [13.3\%] with the CT type, and 8 [25.0\%] with the TT type), showing a statistically significant trend by MTHFR genotype $(\mathrm{p}=0.026)$. Notably, one-quarter of TT-type participants were at risk of NTDs.

Differences in folate consumption and serum folate concentrations between baseline and after the intervention

\section{Intake of folate at baseline and after intervention}

At baseline, no differences were noted in folate intake in the experimental $(\mathrm{n}=73)$ and control $(\mathrm{n}=70)$ groups according to MTHFR genetic polymorphism (Table 3 ). However, after the intervention, folate intakes were consistently higher in the experimental group than in the control group $(\mathrm{p}<0.001)$. Overall, there was an approximately 2.5 -fold increase $(\mathrm{p}<0.001)$ in the experimental group. The changes by MTHFR genotype were as follows: from 137 [31] to 375 [83] $\mu \mathrm{g} / 1,000$ $\mathrm{kcal} /$ day for the CC type, from 161 [46] to 395 [87] $\mu \mathrm{g} / 1,000 \mathrm{kcal} /$ day for the CT type, and from 167 [89] to 419 [136] $\mu \mathrm{g} / 1,000 \mathrm{kcal} /$ day for the TT type. However, there were no differences in these increments according to genetic polymorphism. In the control group, there were no discrepancies between baseline and post-intervention levels by MTHFR genotype.

\section{Serum folate concentrations at baseline and after the intervention}

At baseline, there were no differences in serum folate concentrations within the same polymorphism subgroup in the experimental and control groups. However, serum folate levels were consistently higher with the CC type than with the TT type in the experimental and control groups (Table 4).

In the experimental group, serum folate concentrations significantly increased from baseline to post intervention as follows: from 12.2 [1.3] to $18.5[1.3] \mathrm{ng} / \mathrm{mL}$ for the CC type, from $9.8[1.5]$ to $14.7[1.3] \mathrm{ng} /$ $\mathrm{mL}$ for the CT type, and from 7.9 [1.4] to $11.0[1.3] \mathrm{ng} / \mathrm{mL}$ for the TT type. The change rates were $152.3 \%[1.4 \%]$ for the CC type, $150.8 \%$ [1.4\%] for the CT type, and $144.2 \%$ [1.3\%] for the TT type, without any statistical significant difference by MTHFR genetic polymorphism. In the control group, there were no discrepancies between baseline and post intervention or in the change rates in folate concentrations according to MTHFR genetic polymorphism.

\begin{tabular}{|c|c|c|c|c|c|c|c|}
\hline & \multicolumn{3}{|c|}{ Experimental group $(n=73)$} & \multicolumn{3}{|c|}{ Control group $(n=70)$} & \multirow{2}{*}{$\mathbf{P}^{1)}$} \\
\hline & CC type $(n=16)$ & CT type $(n=41)$ & TT type $(n=16)$ & CC type $(n=20)$ & CT type $(n=34)$ & TT type $(n=16)$ & \\
\hline \multicolumn{7}{|c|}{ Total energy (kcal/day) } & \\
\hline Baseline & 1,629 [383] & $1,577[385]$ & $1,552[445]$ & $1,497[375]$ & $1,607[349]$ & $1,421[235]$ & n.s. \\
\hline Post-intervention & $1,627[419]$ & $1,563[407]$ & $1,570[410]$ & 1,534 [395] & $1,370[417]$ & $1,440[407]$ & n.s. \\
\hline $\mathrm{P}^{2)}$ & n.s. & n.s. & n.s. & n.s. & n.s. & n.s. & \\
\hline \multicolumn{8}{|c|}{ Folate $(\mu \mathrm{g} / 1000 \mathrm{kcal} /$ day $)$} \\
\hline${\text { Baseline }{ }^{3)}}$ & 137 [31] & $161[46]$ & 167 [89] & 187 [81] & $143[44]$ & $170[56]$ & n.s. \\
\hline Post-intervention ${ }^{4)}$ & $375[83]^{a, b, c}$ & $395[87]^{\text {d,e,f }}$ & $419[136]^{g, h, i}$ & $167[51]^{a, d, g}$ & $149[58]^{b, e, h}$ & $170[41]^{\mathrm{cf}, \mathrm{i}}$ & $<0.001$ \\
\hline $\mathrm{P}^{2)}$ & $<0.001$ & $<0.001$ & $<0.001$ & n.s. & n.s. & n.s. & \\
\hline \multicolumn{8}{|c|}{ 1)One-way analysis of variance with post hoc Bonferroni test: statistically significant across the same characters. } \\
\hline \multicolumn{8}{|c|}{ 2) Comparison between baseline vs post-intervention across the same MTHFR genotypes: paired $t$-test. } \\
\hline \multicolumn{8}{|l|}{${ }^{3)}$ Dietary folate. } \\
\hline
\end{tabular}

Table 3: Comparison of baseline vs post-intervention folate consumption by MTHFR genetic polymorphism in the experimental group and control groups (/1,000 kcal).

\begin{tabular}{|c|c|c|c|c|c|c|c|}
\hline & \multicolumn{3}{|c|}{ Experimental group $(n=73)$} & \multicolumn{3}{|c|}{ Control group $(n=70)$} & \multirow[b]{2}{*}{$\mathbf{P}^{1)}$} \\
\hline & CC type $(n=16)$ & CT type $(n=41)$ & $\begin{array}{l}\text { TT type } \\
(n=16)\end{array}$ & CC type $(n=20)$ & CT type $(n=34)$ & TT type $(n=16)$ & \\
\hline Baseline & $12.2[1.3]^{a, b}$ & $9.8[1.5]$ & $7.9[1.4]^{\mathrm{a}, \mathrm{c}}$ & $12.0[1.4]^{\mathrm{cod}}$ & $10.1[1.4]$ & $7.5[1.4]^{\mathrm{b}, \mathrm{d}}$ & $<0.001$ \\
\hline Post-intervention & $18.5[1.3]^{\mathrm{a}, \mathrm{b}, \mathrm{c}, \mathrm{d}}$ & $14.7[1.3]^{e, f, g}$ & $11.0[1.3]^{\mathrm{a}}$ & $10.6[1.4]^{\mathrm{b}, \mathrm{e}}$ & $9.6[1.4]^{\mathrm{c}, \mathrm{f}}$ & $8.0[1.4]^{\mathrm{d}, \mathrm{g}}$ & $<0.001$ \\
\hline Change rate $(\%)$ & $152.3[1.4]^{a, b, c}$ & $150.8[1.4]^{\mathrm{d}, \mathrm{e}, \mathrm{f}}$ & $144.2[1.3]^{\mathrm{g}, \mathrm{h}}$ & $88.3[1.4]^{\mathrm{a}, \mathrm{d}, \mathrm{g}}$ & $95.6[1.3]^{\mathrm{b}, \mathrm{e}, \mathrm{h}}$ & $106.7[1.4]^{\mathrm{c}, \mathrm{f}}$ & $<0.001$ \\
\hline $\mathrm{P}^{2)}$ & $<0.001$ & $<0.001$ & $<0.001$ & n.s. & n.s. & n.s. & \\
\hline
\end{tabular}

Table 4: Serum folate concentrations by MTHFR genetic polymorphism in the experimental and control groups. 

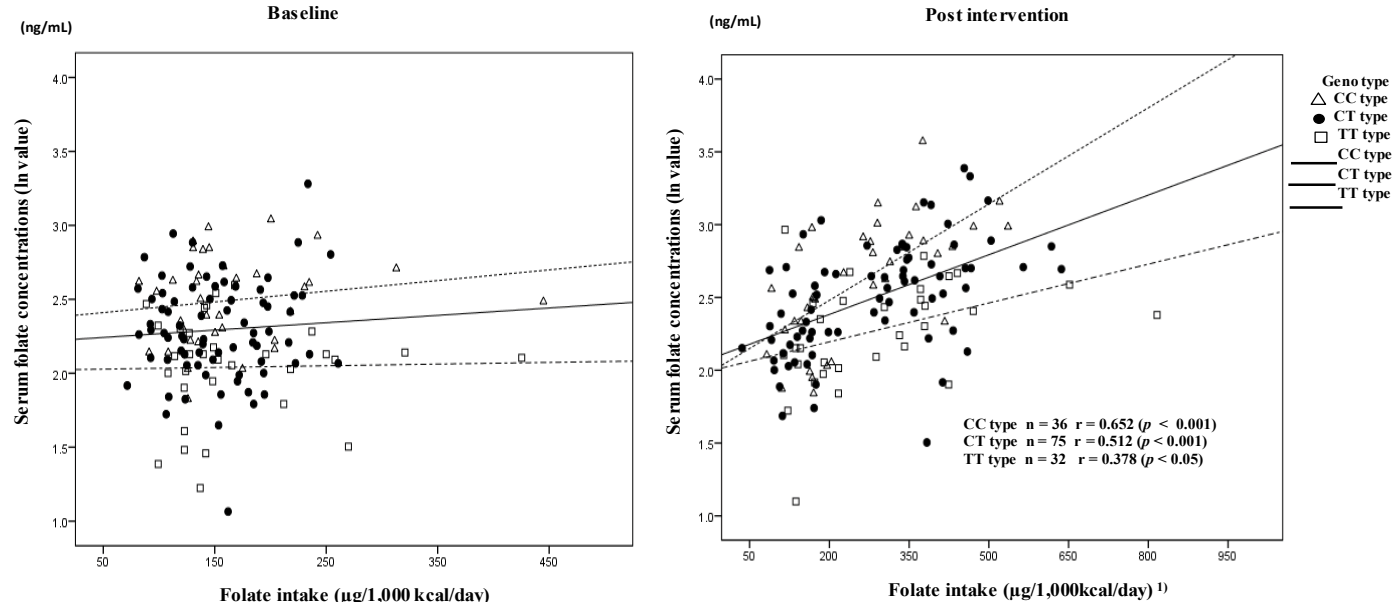

Figure 2: Associations between energy-adjusted folate intake and serum folate concentrations (In value) by MTHFR genetic polymorphism at baseline and post intervention.

1) Folate intake in the post-intervention=dietary folate+dietary folate equivalent for folic acid.

\section{Association of folate intake with serum folate levels at baseline and after the intervention}

At baseline, there were no significant Pearson correlation coefficients between energy-adjusted folate intakes and log-transformed serum folate concentrations by MTHFR genetic polymorphism for all subjects (Figure 2).

After the intervention, the Pearson correlation coefficient ( $\mathrm{r}=0.463)$ was statistically significant overall $(\mathrm{p}<0.001)$, as well as by genotype: $\mathrm{r}=0.652(\mathrm{p}<0.001)$ for the CC type, $\mathrm{r}=0.512(<0.001)$ for the CT type, and $\mathrm{r}=0.378(\mathrm{p}<0.05)$ for the TT type.

\section{Frequency of serum folate concentrations $<7 \mathrm{ng} / \mathrm{mL}$ at baseline and after the intervention}

In the experimental group, the number of participants with serum folate levels $<7 \mathrm{ng} / \mathrm{mL}$ at baseline decreased from 10 (13.7\%) to 2 $(2.7 \%)$ after the intervention ( $\mathrm{p}=0.031$ ) (Table 5): 0 participants before and after the intervention for the CC type, from 6 participants (14.6\%) to $1(2.4 \%)$ for the CT type, and from 4 participants $(25.0 \%)$ to 1 (6.3\%) for the TT type. In the control group, there were no differences in the serum folate concentration $<7 \mathrm{ng} / \mathrm{mL}$ frequency at baseline versus after the intervention by MTHFR genotype.

\section{Discussion}

After stratifying 143 female university students by the MTHFR C677T genetic polymorphism, we conducted an RCT using FF milk containing $200 \mu \mathrm{g}$ of folic acid and studied its effects on serum folate concentrations. At baseline, the average dietary folate intake was 246 [97] $\mu \mathrm{g} /$ day for all subjects, and no discrepancies were noted between the experimental and control groups. There was an approximately 1.5 -fold increase in serum folate levels after the intervention in the experimental group. The intervention reduced the number of participants with serum folate levels lower than the cutoff value for NTDs $(7 \mathrm{ng} / \mathrm{mL}$ ) to one-fifth (from 10 to 2 ). In addition to regular consumption of appropriate food/meals, FF milk could help to reduce the onset of NTDs in all MTHFR genotypes.

At baseline, there were no differences in dietary folate consumption by MTHFR genetic polymorphism but serum folate concentrations showed significant differences according to MTHFR genotype, in the order of CC type >CT type >TT type, which is in line with previous results: CC type/CT type $>$ TT type $[25,26]$, CC type $>$ CT type/TT type [27], and CC type >TT type [28]. There were some discrepancies in the relationships, but there was at least a common trend for CC type $>$ TT type, indicating that there are differences in folate metabolism by MTHFR genetic polymorphism.

In the experimental group, serum folate increased to $152.3 \%$ for the CC type, to $150.8 \%$ for the CT type, and to $144.2 \%$ for the TT type after the FF milk intervention. Thus, all participants exceeded the cutoff value of folate $(4 \mathrm{ng} / \mathrm{mL})$ for megaloblastic anemia, irrespective of MTHFR genotypes. The number of subjects with serum folate concentrations lower than the cutoff value for NTDs $(7 \mathrm{ng} / \mathrm{mL})$ decreased from 10

\begin{tabular}{|c|c|c|c|c|c|c|c|c|c|c|c|c|c|c|c|c|c|c|}
\hline & \multicolumn{8}{|c|}{ Experimental group } & \multicolumn{9}{|c|}{ Control group } & \multirow{3}{*}{$\mathbf{P}^{1)}$} \\
\hline & \multicolumn{2}{|c|}{ Total $(n=73)$} & \multicolumn{2}{|c|}{$\begin{array}{l}\text { CC type } \\
(n=16)\end{array}$} & \multicolumn{2}{|c|}{$\begin{array}{c}\text { CT type } \\
(n=41)\end{array}$} & \multicolumn{2}{|c|}{ TT type $(n=16)$} & \multirow[t]{2}{*}{$\mathbf{P}^{1)}$} & \multicolumn{2}{|c|}{ Total $(n=70)$} & \multicolumn{2}{|c|}{$\begin{array}{l}\text { CC type } \\
(n=20)\end{array}$} & \multicolumn{2}{|c|}{$\begin{array}{c}\text { CT type } \\
(n=34)\end{array}$} & \multicolumn{2}{|c|}{ TT type $(n=16)$} & \\
\hline & $\mathrm{n}$ & $(\%)$ & $\mathrm{n}$ & $(\%)$ & $n$ & $(\%)$ & $\mathrm{n}$ & $(\%)$ & & $\mathrm{n}$ & $(\%)$ & $\mathrm{n}$ & $(\%)$ & $\mathrm{n}$ & $(\%)$ & $\mathrm{n}$ & $(\%)$ & \\
\hline Baseline & 10 & $(13.7)$ & 0 & $(0)$ & 6 & $(14.6)$ & 4 & $(25.0)$ & n.s. & 9 & (12.9) & 1 & $(5.0)$ & 4 & $(11.8)$ & 4 & $(25.0)$ & n.s. \\
\hline Post-intervention & 2 & $(2.7)$ & 0 & (0) & 1 & $(2.4)$ & 1 & $(6.3)$ & n.s. & 11 & $(15.7)$ & 2 & $(10.0)$ & 5 & $(14.7)$ & 4 & $(25.0)$ & n.s. \\
\hline $\mathrm{P}^{2)}$ & \multicolumn{2}{|c|}{0.031} & & & \multicolumn{2}{|r|}{ n.s } & \multicolumn{2}{|r|}{ n.s } & & \multicolumn{2}{|c|}{ n.s. } & \multicolumn{2}{|r|}{ n.s. } & \multicolumn{2}{|r|}{ n.s. } & \multicolumn{2}{|r|}{ n.s. } & \\
\hline
\end{tabular}


(13.7\%) to $2(2.7 \%)$. Moreover, the serum folate levels of the subjects were just below the cutoff value, that is, $6.7 \mathrm{ng} / \mathrm{mL}$ and $6.8 \mathrm{ng} / \mathrm{mL}$, suggesting that the present intervention using FF milk containing 200 $\mu \mathrm{g}$ of folic acid manifested satisfactory results for the risk reduction of NTDs.

In order to clarify the minimum effective dose of folic acid for the prevention of NTDs, Daly et al [29] carried out an RCT using supplements containing 100,200 , or $400 \mu \mathrm{g}$ of folic acid or placebo for approximately 6 months and evaluated the effects using $400 \mathrm{ng} / \mathrm{mL}$ of red blood cell folate concentration as reference. They concluded that $400 \mu \mathrm{g} /$ day of folic acid effectively prevented NTDs but was subjected to extra monetary cost, whereas $200 \mu \mathrm{g}$ /day appeared favorable in terms of cost-effectiveness, cost-benefit, and risk-benefit appraisals, as also reviewed by Dary et al. [24]. Furthermore, even a supplement containing $100 \mu \mathrm{g}$ of folic acid when consumed continuously could help to reduce NTD development.

Regarding Japanese interventions, Hiraoka et al. [27] conducted an intervention study in female university students using supplements containing $200 \mu \mathrm{g} / \mathrm{day}$ or $400 \mu \mathrm{g} /$ day of folic acid for 4 weeks and observed elevated serum folate concentrations to $140 \%$ or $173 \%$ on average after the intervention. Kawashima et al. [30] conducted a doubleblind placebo controlled trial in women aged in their 20 s by applying a mixed vegetable and fruit juice capsule containing $420 \mu \mathrm{g} /$ day of folate in addition to regular meals for 28 days and determined a serum folate concentration increase of 22.4 [1.26] ng/mL (174\% elevation compared with baseline) and a decreased plasma homocysteine level of 8.14 [0.44] $\mathrm{nmol} / \mathrm{mL}$ (81.1\% of baseline), suggesting that the intervention could reduce the development of both NTDs and megaloblastic anemia. These observations were equivalent to the meta-analysis observations by Marchetta et al. [31] showing that a 1,070 nmol/L red blood cell folate level (the lower limit for the prevention of NTDs) was attained by consumption of $450 \mu \mathrm{g} / \mathrm{day}$ of folate from natural food items.

For the purpose of international comparisons, we applied a 1.7 DFE in the present study. Meanwhile, in Japan, a 2.0 DFE was adopted in the report by Fukuwatari et al [32]. Thus, FF milk containing $200 \mu \mathrm{g}$ of folic acid was considered to be the equivalent to 340 or $400 \mu \mathrm{g} /$ day of dietary folate and approximately equal to the folate intakes estimated by Kawashima et al. [30] and Marchetta et al. [31].

Young Japanese women, even pregnant women, are reported to have insufficient knowledge of NTDs, the association between folate and NTDs, and the importance of periconceptionally folate consumption. Recommendations to consume $400 \mu \mathrm{g} / \mathrm{day}$ or more of folic acid were issued to women potentially expecting to become pregnant and women in early gestation, but only $20 \%-30 \%$ of women deliberately conceived. Because the fetal neural tube closes during early pregnancy, desirable folate nutrition should be provided during this critical period. Many countries, including the United States, have launched a populationwide approach involving cereals (wheat, maize, flour) fortified with folic acid. Thus, folic acid fortification to rice (a Japanese staple) may be an option, but rice consumption has drastically declined in recent years and should not be chosen. Accordingly, a recommendation to partly replace milk with FF milk seems acceptable because the Food Balance Guide, Japan recommends the regular consumption of a given amount of milk. The strategy would not only reduce the risk of NTDs but also increase calcium consumption, which is known to be insufficient in the Japanese population.

Japanese people would prefer to consume nutrients from palatable food rather than supplements. In fact, there are wide varieties in the quality of supplements (including ingredients), and some appear to lack quality and safety guarantees. Thus, the National Institute of Health and Nutrition, Japan issued the following three recommendations for individuals with a folate intake deficiency; women should consume folate first from various food items/meals, then folic acid-fortified foods or foods with health claims, and then folic acid supplements [33]. Using information on the individual MTHFR genotype, tailor-made safe, effective, and efficient health care/prevention using palatable food could be implemented.

There are limitations to the present trial. The study subjects were limited to female university students, the sample size was rather small, and the intervention period was relatively short. In addition, we did not assay the folate levels of the red blood cells and plasma homocysteine. There might have been some lower adherence to the regimen in the experimental group. A certain level of contamination might have affected the control group although we asked the subjects not to consume FF milk. We should explore the possible effects of food (other than milk) containing or fortified with folic acid because the relative bioavailability differs by food item. Further tailor-made trials that consider MTHFR genotype are warranted to safely optimize and maximize the ability of folate and folic acid to reduce the risk of NTDs.

In conclusion, there are no differences in the consumption of folate according to the MTHFR C677T genetic polymorphism, but serum folate concentrations at baseline were in the following order: CC type $>$ CT type > TT type. Consumption of FF milk containing $200 \mu \mathrm{g} /$ day folic acid sufficiently increased serum folate concentrations up to the cutoff value for NTDs in female university students and seemed to effectively and efficiently decrease the risk of NTDs. FF milk could be selected as a food before and during the early period of gestation, in addition to regular favorable meals, for the safe prevention of NTDs.

\section{Acknowledgment}

We are grateful to the female students who participated in the present intervention trial and to Yakult Honsha Co. Ltd.

\section{Conflicts of Interest}

Fermented milk fortified with $200 \mu \mathrm{g} /$ day of folic acid was provided by commercial company (Yakult Honsha Co. Ltd.) free of charge, but we declare that there was no conflict of interest.

\section{References}

1. Smithells RW, Sheppard S, Schorah CJ (1976) Vitamin deficiencies and neural tube defects. Arch Dis Child 51: 944-950.

2. MRC Vitamin Study Research Group (1991) Prevention of neural tube defects: results of the medical research council vitamin study. Lancet 338: 131-137.

3. Czeizel AE, Dudás I (1992) Prevention of the first occurrence of neural-tube defects by periconceptional vitamin supplementation. N Engl J Med 327: 18321835

4. Milunsky A, Jick H, Jick SS, Bruell CL, MacLaughlin DS, et al. (1989) Multivitamin/folic acid supplementation in early pregnancy reduces the prevalence of neural tube defects. JAMA 262: 2847-2852.

5. Werler MM, Shapiro S, Mitchell AA (1993) Periconceptional folic acid exposure and risk of occurrent neural tube defects. JAMA 269: 1257-1261.

6. Institute of Medicine (1998) Dietary Reference Intakes for Thiamin, Riboflavin Niacin, Vitamin B6, Folate, Vitamin B12, Pantothenic Acid, Biotin, and Choline. National Academy Press, Washington DC

7. Scientific Advisory Committee on Nutrition (2006) Report on Health and Socia Subjects 41DietaryReferenceValues DRVs for Food energy and Nutrients for the UK.https://www.gov.uk/government/uploads/system/uploads/attachment data/file/338892/SACN_Folate_and_Disease_Prevention_Report.pd.

8. Berry RJ, Li Z, Erickson JD, Li S, Moore CA, et al. (1991) Prevention of neuraltube defects with folic acid in China. N Engl J Med 341: 1485-1490.

9. Ministry of Health, Labour, and Welfare, Japan (2000) Information on consumption of folic acid in order to reduce children affected with neural 
Citation: Mitsuguchi C, Kumagai Y, Yasutomo H, Ito Y, Kitagawa M, et al. (2017) Effects of Folic Acid-Fortified Milk Consumption on Serum Folate Levels in Japanese Female Students: a Randomized Controlled Trial Stratified by Methylenetetrahydrofolate Reductase C677T Genetic Polymorphism. Vitam Miner 6: 170.

defects to women of childbearing age. http://www.mhlw.go.jp/houdou/2006/02/ dl/h0201-3a3-03c.pdf.

10. Bixenstine PJ, Cheng TL, Cheng D, Connor KA, Mistry KB (2015) Association between preconception counseling and folic acid supplementation before pregnancy and reasons for non-use. Matern Child Health J 19: 1974-1984.

11. Bestwick JP, Huttly WJ, Morris JK, Wald NJ (2014) Prevention of neural tube defects: a cross-sectional study of the uptake of folic acid supplementation in nearly half a million women. PLoS One 19: 9

12. McNulty B, Pentieva K, Marshall B, Ward M, Molloy AM, et al. (2011) Women's compliance with current folic acid recommendations and achievement of optimal vitamin status for preventing neural tube defects. Hum Reprod 26 1530-1536.

13. Forster DA, Wills G, Denning A, Bolger M (2009) The use of folic acid and other vitamins before and during pregnancy in a group of women in Melbourne, Australia. Midwifery 25: 134-146.

14. Sato Y, Nakanishi T, Chiba T, Yokotani K, Ishinaga K, et al. (2013) Prevalence of inappropriate dietary supplement use among pregnant women in Japan. Asia Pac J Clin Nutr 22: 83-89.

15. Sato Y, Nakanishi T, Chiba T, Umegaki K (2014) Attitudes of pregnan Japanese women and folic acid intake for the prevention of neural tube defects: a nationwide Internet survey. Nihon Koshu Eisei Zasshi 61: 321-332.

16. Kondo A, Morota N, Date H, Yoshifuji K, Morishima T, et al. (2015) Awareness of folic acid use increases its consumption, and reduces the risk of spina bifida. Br J Nutr 14: 84-90.

17. Ministry of Health, Labour, and Welfare, Japan (2017) National Health and Nutrition Survey 2014. http://www.mhlw.go.jp/file/04-Houdouhappyou10904750-Kenkoukyoku-Gantaisakukenkouzoushinka/0000117311.pdf. (in Japanese)

18. Ministry of Health, Labour and Welfare (2015) Overview of dietary reference intakes for Japanese. http://www.mhlw.go.jp/file/06-Seisakujouhou10900000-Kenkoukyoku/Overview.pdf

19. Bailey LB (1998) Dietary reference intakes for folate: the debut of dietary folate equivalents. Nutr Rev 56: 294-299.

20. Yang TL, Hung J, Caudill MA, Urrutia TF, Alamilla A, et al. (2005) A long-term controlled folate feeding study in young women supports the validity of the 1.7 multiplier in the dietary folate equivalency equation. Am Soc Nutr Sci Nutr 135 $1139-1145$.

21. Tokudome S, Ikeda M, Tokudome Y, Imaeda N, Kitagawa I, et al. (1998) Development of data-based semi-quantitative food frequency questionnaire for dietary studies in middle- aged Japanese. Jpn J Clin Oncol 28: 679-687.

22. Ministry of Education, Culture, Sports, Science and Technology (2010) Standard Tables of Food Composition in Japan 2010. Ministry of Education, Culture, Sports, Science and Technology, Tokyo.

23. Selhub J, Jacques PF, Dallal G, Choumenkovitch S, Rogers G (2008) The use of blood concentrations of vitamins and their respective functional indicators to define folate and vitamin B12 status. Food Nutr Bull 29: 567-573.

24. Dary O (2009) Nutrition interpretation of folic acid intervention. Nutr Rev 67 235-244.

25. Crider KS, Zhu JH, Yang QH, Ginder J, Maneval DR, et al. (2011) MTHFR $677 \mathrm{C} \rightarrow$ T genotype is associated with folate and homocysteine concentrations in a large, population- based, double-blind trial of folic acid supplementation. Am J Clin Nutr 93: 1365-1372.

26. Nishio K, Goto $Y$, Kondo T, Ito S, Ishida Y, et al. (2008) Serum folate and methylenetetrahydrofolate reductase (MTHFR) C677T polymorphism adjusted for folate intake. J Epidemiol 18: 125-131.

27. Hiraoka M, Kato K, Saito Y, Yasuda K, Kagawa Y (2004) Gene-nutrien and gene-gene interactions of controlled folate intake by Japanese women. Biochem Biophys Res Commun 316: 1210-1216.

28. Ashfield-Watt PAL, Pullin $\mathrm{CH}$, Whiting JM, Clark ZE, Moat SJ, et al (2002) Methylenetetrahydrofolate reductase $677 \mathrm{C} \rightarrow \mathrm{T}$ genotype modulates homocysteine responses to a folate-rich diet or a low-dose folic acid supplement: a randomized controlled trial. Am J Clin Nutr 76: 180-186.

29. Daly S, Mills JL, Molloy AM, Conley M, Lee YJ, et al. (1997) Minimum effective dose of folic acid for food fortification to prevent neural-tube defects. Lance 350:1666-1669.

30. Kawashima A, Madarame T, Koike H, Komatsu Y, Wise JA (2007) Four week supplementation with mixed fruit and vegetable juice concentrates increased protective serum antioxidants and folate and decreased plasma homocysteine in Japanese subjects. Asia Pac J Clin Nutr 16: 411-421.

31. Marchetta CM, Devine OJ, Crider KS, Tsang BL, Cordero AM, et al. (2015) Assessing the association between natural food folate intake and blood folate concentrations: a systematic review and Bayesian meta-analysis of trials and observational studies. Nutrients 7: 2663-2686.

32. Fukuwatari T, Shibata K (2009) Relative availability of water-soluble vitamins in a white bread diet to free vitamins. J Home Econ Jpn 60: 57-63.

33. National Institute Health and Nutrition, Japan (2013). http://hfnet.nih.go.jp/ contents/detail $1550 . \mathrm{html}$ 